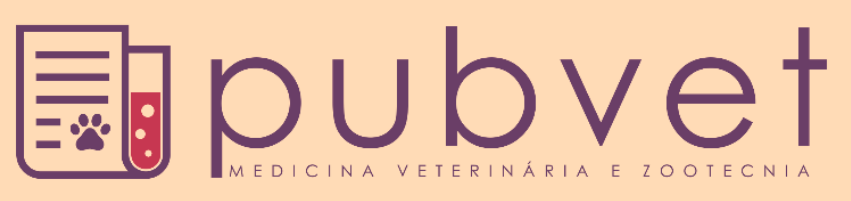

https://doi.org/10.31533/pubvet.v15n01a737.1-4

\title{
Hiperplasia mamária felina: Relato de caso
}

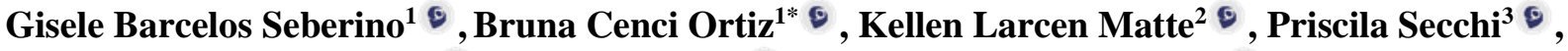 \\ Veridiane da Rosa Gomes $^{3}{ }^{\circ}$, Dalila Pozzatti ${ }^{\circ}$, Karina Godet Figueiredo $^{50}$ \\ ${ }^{1}$ Médica Veterinária Residente de Clínica Médica de Pequenos Animais do Hospital Veterinário da Universidade Lutera do Brasil. Canoas-RS, Brasil. \\ ${ }^{2}$ Acadêmica do curso de Medicina Veterinária da Universidade Luterana do Brasil, Departamento de Medicina Veterinária. Canoas-RS, Brasil. \\ ${ }^{3}$ Médica Veterinária do Hospital Veterinánio da Universidade de Passo Fundo, Departamento de Patologia Clínica. Passo Fundo, Rio Grande do Sul, Brasil. \\ ${ }^{4}$ Acadêmica do curso de Medicina Veterinária do Centro Universitário Ritter dos Reis, Porto Alegre, Rio Grande do Sul, Brasil. \\ ${ }^{5}$ Médica Veterinária Autônoma. Rio de Janeiro-RJ, Brasil. \\ *Autor para correspondência,E-mail: bruna.ortizvet@hotmail.com
}

Resumo. A hiperplasia mamária felina é uma condição não neoplásica, caracterizada por rápida hipertrofia e hiperplasia ou proliferação do estroma e epitélio ductal das glândulas mamárias e acomete normalmente gatas jovens não castradas. As gatas acometidas manifestam na sua maioria as mamas aumentadas, edemaciadas, ulceradas, além de outros sinais inespecíficos. O diagnóstico pode ser dado através do histórico e exame clínico, porém confirmado apenas com exame histopatológico da lesão. Este estudo relata o caso de uma gata, não castrada, SRD, de apenas 3 meses de idade. Foi atendida com a queixa de um aumento de volume na região abdominal há cerca de três semanas, com crescimento rápido há sete dias. Neste caso, o aspecto clínico e histórico do paciente ainda muito jovem, sem ter manifestado seu primeiro estro, foram atípicos. Assim, sugeriu-se primeiramente se tratar de outra patologia, que foi descartada após exame de imagem e no momento cirúrgico. Onde optou-se pela remoção da massa através de mastectomia parcial, confirmando o diagnóstico de hiperplasia mamária felina ao exame histopatológico.

Palavras-chave: Desordem, gata, glândula, hormonal

\section{Feline breast hyperplasia: Case report}

\begin{abstract}
Feline mammary hyperplasia is a non-neoplastic condition, characterized by daily hypertrophy and hyperplasia or proliferation of the stroma and ductal epithelium of the mammary glands and usually affects young uncastrated cats. The most affected cats manifest enlarged, swollen, ulcerated breasts, in addition to other nonspecific signs. The diagnosis can be given through the history and clinical examination, but confirmed only with histopathological examination of the lesion. This study reports the case of an uncastrated cat, only 3 months old. It was attended with complaints of an increase in volume in the abdominal region about 3 weeks ago, with rapid growth 7 days ago. In this case, the clinical and historical aspect of the still very young patient, without having manifested his first estrus, were atypical. Thus, in addition to the fact that the imaging test was suspected, it was first suggested to be another pathology, which was discarded at the surgical moment, where the mass was removed by partial mastectomy, being confirmed the diagnosis of feline mammary hyperplasia at histopathological examination.
\end{abstract}

Keyword: Cat, disorder, mammary, hormonal, mastectomy

\section{Hiperplasia mamaria felina: Reporte de un caso}

Resumen. La hiperplasia mamaria felina es una afección no neoplásica, caracterizada por hipertrofia rápida e hiperplasia o proliferación del estroma y el epitelio ductal de las 
glándulas mamarias y generalmente afecta a gatas jóvenes no castradas. Las gatas afectadas manifiestan principalmente mamas aumentadas, hinchadas y ulceradas, además de otros signos inespecíficos. El diagnóstico se puede dar a través de la historia y el examen clínico, pero se confirma solo con el examen histopatológico de la lesión. Este estudio informa el caso de una gata, no castrada, mestiza, de solo 3 meses de edad. Fue atendida con una queja de un aumento en el volumen en la región abdominal hace aproximadamente 3 semanas, con un rápido crecimiento durante 7 días. En este caso, el aspecto clínico e histórico del paciente, aún muy joven, sin haber manifestado su primer celo, era atípico. Por lo tanto, primero se sugirió que era otra patología, que se descartó después de la imagen y en el momento de la cirugía, donde se decidió extirpar la masa mediante una mastectomía parcial, confirmando el diagnóstico de hiperplasia mamaria felina en el examen histopatológico.

Palabras clave: Transtorno, gata, glândula, hormonal

\section{Introdução}

A hiperplasia mamária felina é uma afecção não neoplásica, caracterizada por rápida hipertrofia e hiperplasia do estroma e epitélio ductal das glândulas mamárias (Amorim, 2007; Filgueira et al., 2008; Viana et al., 2012). Acomete normalmente gatas jovens inteiras após o estro, mas já foi descrita em gatos e gatas castradas após uso de medicações contraceptivas (Bojrab, 2014). Mais de uma glândula costuma estar acometida, aumentadas devido ao estimulo hormonal (Amorim, 2007; Filgueira et al., 2008; Viana et al., 2012). Podem manifestar sinais como febre, anorexia, depressão (Bojrab, 2014), glândulas mamárias vermelhas, edemaciadas, firmes, indolores, com bordas bem definidas que podem ser facilmente separadas da parede abdominal (Bojrab, 2014). Úlceras cutâneas, necrose e infecção bacteriana secundária podem ocorrer (Amorim, 2007; Filgueira et al., 2008; Viana et al., 2012).

O diagnóstico é feito pelo histórico e sinais clínicos, sendo o diagnóstico definitivo dado pela análise histopatológica (Amorim, 2007; Filgueira et al., 2008; Viana et al., 2012). Raskin \& Meyer (2003) descrevem camadas moderadas a grandes de células epiteliais mamárias hiperplásicas, com núcleos arredondados de tamanho e forma uniforme e quantidade escassa a moderada de citoplasma basofílico. Podem ser observados macrófagos e células espumosas. A citologia é desaconselhada, pois pode ser confundida com neoplasias benignas.

O tratamento consiste na retirada do estímulo hormonal endógeno ou exógeno. A ovariohisterectomia deve ser realizada preferencialmente após regressão natural da doença. Em alguns casos pode ser necessário a realização de mastectomia parcial ou radical, quando os tratamentos clínicos não se mostrarem eficazes ou em apresentações mais graves da doença (Bojrab, 2014). O prognóstico é favorável, porém alguns casos em que os animais demonstram certo grau de morbidade e que podem vir a óbito devido a complicações (Cogliati et al., 2015; Jericó et al., 2015).

Este trabalho relata um caso de hiperplasia mamária felina, em uma gata de 3 meses de idade, com apresentação atípica, onde apenas uma glândula mamária foi acometida e o diagnóstico foi dado por exame histopatológico.

\section{Relato de caso}

Um felino, SRD, fêmea, inteira, com três meses de idade, pesando $1,15 \mathrm{~kg}$, foi atendida com queixa de secreção ocular bilateral e aumento de volume em região abdominal, há aproximadamente três semanas (desde a adoção do animal), com crescimento acentuado a uma semana. Os tutores não souberam informar se houve histórico de trauma anterior à adoção. Alimentava-se, urinava e defecava normalmente e o outro felino contactante da mesma ninhada não manifestava nenhum sinal clínico aparente. $\mathrm{O}$ felino não havia sido vacinado nem vermifugado até a presente ocasião e estava recebendo amoxicilina com clavulanato há sete dias devido a um anterior diagnóstico de complexo respiratório felino feito em outro estabelecimento. Ao exame clínico, o paciente se encontrava em bom estado geral, FC >200 bpm, TR 38, $8^{\circ} \mathrm{C}$, taquipneico, muito desconforto à palpação abdominal e demais parâmetros dentro da normalidade. Foi observada uma massa na região inguinal direita, que envolvia M4, medindo aproximadamente $8 \mathrm{~cm}$, de consistência macia e algumas regiões bem firmes, com aspecto congesto e intensa algia (Figura 1). Não foi possível palpar um anel herniário. 
Foi realizado hemograma completo que revelou leucocitose $(29.400 \mu / \mathrm{L})$, neutrofilia (segmentados $23.226 \mu / \mathrm{L})$ e trombocitopenia $(98.000 \mu / \mathrm{L})$. O exame ultrassonográfico foi realizado para descartar outras possíveis causas do aumento de volume. $\mathrm{O}$ animal foi internado para remoção cirúrgica e posterior análise da massa.

Para realização do procedimento cirúrgico foi utilizado como MPA metadona na dose de $0,1 \mathrm{mg} / \mathrm{kg} \mathrm{IM}$ e diazepan $0,5 \mathrm{mg} / \mathrm{kg}$ IV e utilizada solução de ringer com lactato em infusão. Para indução foi utilizado propofol $3 \mathrm{mg} / \mathrm{kg}$ IV e mantido com máscara de isoflurano ao efeito. Realizou-se uma incisão elíptica em torno da massa, divulsionada até a parede abdominal e feita a exérese da mesma, realizando um procedimento de mastectomia parcial. Foi realizado então a redução de espaço morto e reaproximação tecidual com fio de ácido poliglicólico 3-0 em dois planos de sutura, em padrão isolado simples e realizada a dermorrafia com fio mono filamentar de poliamida 3-0 em padrão intradérmico. O exame histopatológico da massa removida (Figura 2), mostrou tratar-se de uma lesão constituída por células epiteliais luminais da glândula mamária, envoltas por células fibroblásticas com matriz mixóide, confirmando o diagnóstico de lesão fibroadenomatosa característica de hiperplasia mamária felina (HMF).

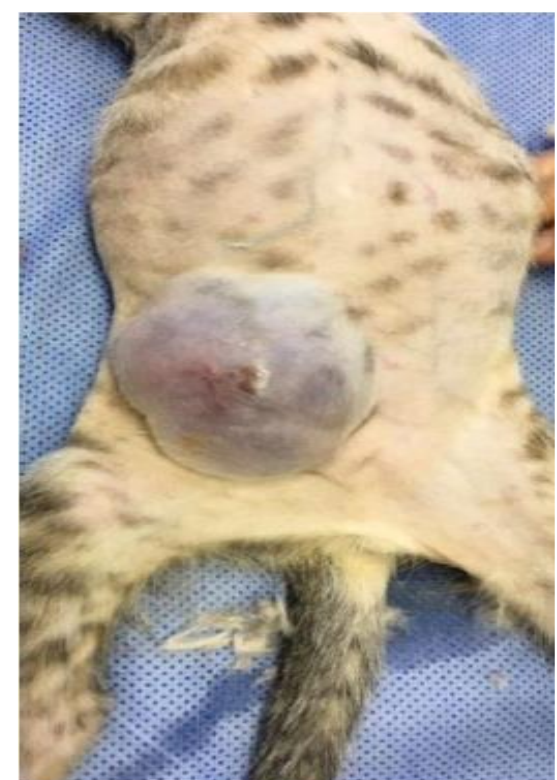

Figura 1. Aumento de volume em região inguinal direita. Notar aspecto congesto, firme e delimitado da massa.

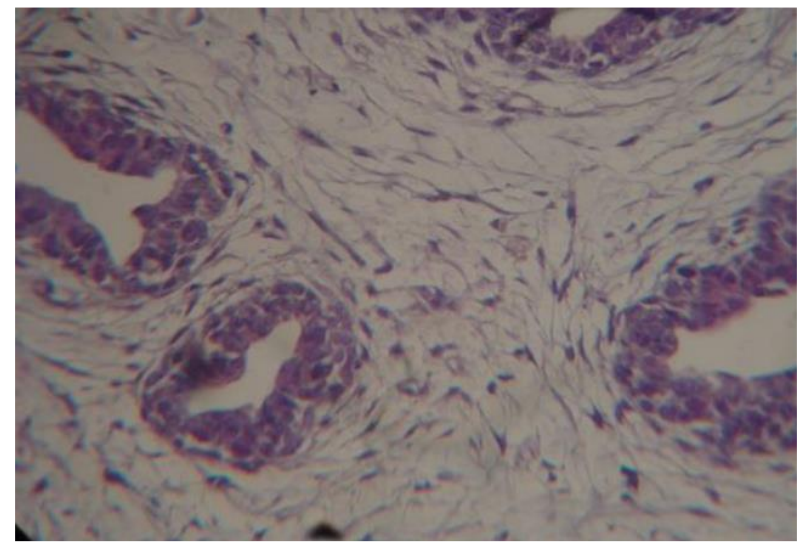

Figura 2. Análise histopatológica constituída por células epiteliais luminais da glândula mamária, envoltas por células fibroblásticas com matriz mixóide.

O paciente permaneceu internado por 4 dias após procedimento, onde recebeu maxican $0,1 \mathrm{mg} / \mathrm{kg}$ uma única aplicação IV, amoxicilina com clavulanato na dose de $20 \mathrm{mg} / \mathrm{kg}$ BID, PO; dipirona $25 \mathrm{mg} / \mathrm{kg}$ $\mathrm{BID}, \mathrm{SC}$ e tramadol $1 \mathrm{mg} / \mathrm{kg}$ TID, SC, além de limpeza dos pontos cirúrgicos com solução fisiológica e vermífugo de amplo espectro. Após receber alta, foi recomendado que desse continuidade na limpeza da ferida cirúrgica, uso de amoxicilina com clavulanato e recomendado posteriormente a ovariohisterectomia. Passados 15 dias, não havendo retorno para remoção dos pontos cirúrgicos, foi feito contato telefônico e relatado boa recuperação do paciente.

\section{Discussão}

A HMF é uma enfermidade relativamente comum na rotina clínica de felinos, que acomete preferencialmente gatas jovens, prenhes ou não, normalmente após o estro. Porém pode também acometer gatos machos ou fêmeas, mais velhos, castrados ou não, após terapia hormonal com estrógenos ou progestágenos (Crivellentin \& Borin-Crivelletin, 2015). Vimos que no referido caso, a enfermidade ocorreu antes mesmo do primeiro ciclo estral e mesmo que seja descrito em gatas jovens, esta ocorreu em idade ainda mais precoce que o comumente observado.

Segundo Amorim (2007), Viana et al. (2012) e Little (2016), a condição clínica normalmente esperada, se dá pelo aumento rápido e progressivo de todas as mamas da cadeia bilateralmente, aspecto macio da lesão e os felinos não manifestam dor a palpação. Diferentemente deste estudo de caso, onde 
apenas uma mama foi acometida, seu aspecto também era firme e manifestava dor à manipulação de toda a região acometida, provavelmente devido a congestão dos vasos sanguíneos locais, o que levou a outras especulações diagnósticas, juntamente com o histórico de adoção recente. Há outros relatos de apenas uma glândula mamária estar envolvida (Amorim, 2007; Filgueira et al., 2008; Viana et al., 2012).

As alterações laboratoriais encontradas, seguiram dentro do esperado para a patologia e condição do animal, onde a leucocitose e trombocitopenia podem ser resultados de um processo inflamatório, infecção bacteriana secundária e visto que, ao trabalhar com a espécie felina, podemos encontrar alterações por estresse no momento em que a coleta foi realizada. Os exames de imagem são utlizados com o intuito de avaliar o padrão da lesão e ajudar na diferenciação de massas de origem maligna (Payan-Carreira, 2013) ou traumáticas. O único método para confirmação do diagnóstico é a histopatologia (Amorim, 2007), conforme foi realizado.

Apesar de primeiramente o tratamento clínico mais a ovariohistecrectomia serem de escolha, em casos de alterações mais localizadas, que comprometam apenas uma ou duas mamas, com muito comprometimento tecidual, a mastectomia parcial pode ser necessária, tendo sido recocomendada a ovariohisterectomia posteriormente á recuperação do paciente (Silva, 2003).

\section{Conclusão}

A hiperplasia mamária felina é de ocorrência relativamente comum, acomete em sua maioria gatas jovens, não castradas, após o estro, ou com histórico de uso de estrógenos ou progestágenos. Podendo acometer gatas muito jovens, antes até do início da sua idade reprodutiva. Observa-se um aumento generalizado das glândulas mamárias, normalmente bilateral, mas em alguns casos, ainda que não seja comum, pode acometer apenas uma glândula mamária isoladamente. O diagnóstico pode ser sustentado pelo histórico e exame clínico, porém apenas pode ser confirmado através de biópsia e exame histopatológico. O tratamento clínico pode ser feito com medicamentos antiprogestágenos, retirada do estímulo hormonal exógeno, quando houver, ou endógeno, devendo ser indicada a ovariohisterectomia. Em alguns casos de apresentações mais graves, a mastectomia pode ser necessária.

\section{Referências}

Amorim, F. V. (2007). Hiperplasia mamária felina. Acta Scientiae Veterinariae, 35(2), 279-280.

Bojrab, M. J. (2014). Mecanismos da moléstia na cirurgia dos pequenos animais. Roca, Brasil.

Cogliati, B., Silva, R. D., \& Ushikoshi, W. S. (2015). Doenças hepáticas caninas. In M. M. Jerico, J. P., Andrade Neto, \& M. M. Kogika (Eds.), Tratado de medicina interna de cães e gatos. Rio de Janeiro: Roca, vol.1 v. p. 1035-1043. (Vol. 1, pp. 1035-1043). Roca.

Crivellentin, L. Z., \& Borin-Crivelletin, S. (2015). Casos de rotina em medicina veterinária de pequenos animais. In MedVet.

Filgueira, K. D., Costa, P. F. C. R., \& Paula, V. V. (2008). Hiperplasia mamária felina: sucesso terapêutico com o uso do aglepristone. Ciência Animal Brasileira, 9(4), 1010-1016.

Jericó, M. M., Kogika, M. M., \& Andrade Neto, J. P. (2015). Tratado de medicina interna de cães e gatos. Guanabara Koogan.

Little, S. E. (2016). O gato: medicina interna. Editora Roca.

Payan-Carreira, R. (2013). Feline mammary fibroepithelial hyperplasia: a clinical approach. Intech Open Science, 8, 215-232. DOI: https://doi.org/10.5772/55550

Raskin, R. E., \& Meyer, D. J. C. (2003). Atlas de citologia de cães e gatos. Roca.

Silva, C. R. N. (2003). Mastectomia. In G. A. Mazzotti \& M. R. Roza (Eds.), Medicina felina essential: guia prético. Livros de Veterinárias.

Viana, D. C., Santos, A. C., Rui, L. A., Oliveira, D. M., Silva, A. B., Costa, F. C. F. C., \& Assís Neto, A. C. (2012). Hiperplasia mamária felina: Um relato de caso. Veterinária Notícias, 18(2).

\section{Histórico do artigo:}

Recebido: 20 de julho, 2020

Aprovado: 22 de agosto, 2020.

Disponível online: 23 novembro, 2020
Licenciamento: Este artigo é publicado na modalidade Acesso Aberto sob a licença Creative Commons Atribuição 4.0 (CC-BY 4.0), a qual permite uso irrestrito, distribuição, reprodução em qualquer meio, desde que o autor e a fonte sejam devidamente creditados 